\title{
DANDO DE COMER A CRISTO Y BENDICIENDO LA MESA: ENTRE FRANCISCO PACHECO Y EL JOVEN DIEGO VELÁZQUEZ
}

\author{
BRINGING FOOD TO CHRIST AND BLESSING \\ AT THE TABLE: BETWEEN FRANCISCO PACHECO \\ AND A YOUNG DIEGO VELÁZQUEZ
}

\author{
FERNANDO MARÍAS \\ Universidad Autónoma de Madrid-Real Academia de la Historia. España \\ ORCID: 0000-0003-1943-5525 \\ fernando.marias@uam.es
}

\begin{abstract}
Este artículo estudia el lienzo de Francisco Pacheco Cristo servido por los ángeles (Castres, Musée Goya) en relación con su precedente de Pablo de Céspedes, sus fuentes textuales religiosas y su función litúrgica para la bendición de la mesa en el refectorio de un convento femenino. También señala la presencia de una pieza de loza idéntica a la que aparece en La educación de la Virgen de la Yale University Art Gallery de New Haven, reforzando la atribución del fragmento francés y el lienzo americano al joven discípulo de Pacheco, Diego Velázquez.

Palabras clave: Pacheco; Céspedes; Velázquez; pintura sevillana; liturgia.
\end{abstract}

This essay analyzes Francisco Pacheco's Christ Served by the Angels in the Wilderness at Castres Musée Goya, in relationship with Pablo de Céspedes's earlier canvas, its religious textual sources and its liturgical function in a nunnery refectory for the blessing at the table. It will also point out the presence of a piece of earthenware that is identical to young Velázquez one in the Yale University Art Gallery The Education of the Virgin; both fragments would reinforce the attribution of the detail and the canvas to Pacheco's disciple.

Keywords: Pacheco; Céspedes; Velázquez; Sevillian painting; liturgy.

* Este trabajo se ha realizado en el marco del Proyecto de investigación "Hacia Antonio Acisclo Palomino. Teoría e historiografía artística del Siglo de Oro", HAR201679442-P del Ministerio de Ciencia e Innovación (MICINN). 
En 1724, a menos de ochenta años de su muerte, Palomino nos dio una contradictoria biografía de Francisco Pacheco (Francisco Pérez del Río, Sanlúcar de Barrameda, 1564-Sevilla, 1644); como nacido en Sevilla hacia 1580 y fallecido en 1654 , de una muy ilustre familia ${ }^{1}$ que le habría permitido llegar -como su hermano Juan Pérez Pacheco- a familiar del Santo Oficio de la Inquisición y censor de las pinturas sagradas en 1618²; como discípulo del desconocido Luis Fernández y viajero a Italia durante varios años y dos -hacia 1610-1611 (septiembre de 1610 a octubre de 1611) - a la corte de Madrid $^{3}$. Citó también entre sus obras más señaladas los entre seis y nueve grandes lienzos de la Merced calzada (1599/1600-1611) de Sevilla, el hoy perdido Arcángel San Miguel de San Alberto (1637) ${ }^{4}$, del Juicio Final (1610-1611) de Santa Isabel (Figuras 1-2)5 , y

${ }^{1}$ En 20 de marzo de 1601 se registró el expediente de limpieza de sangre de Pacheco y sus hermanos Juan, Pedro y Mateo. RODRÍGUEZ MARÍN, Francisco: Francisco Pacheco Maestro de Velázquez. Madrid, 1923, pp. 40-45.

${ }^{2}$ En 1616 había sido nombrado por el Ayuntamiento veedor del oficio de pintores.

3 Véase en general, VALDIVIESO, Enrique y SERRERA, Juan Miguel: Pintura sevillana del primer tercio del siglo XVII. Madrid, 1985, pp. 16-116; CACHO CASAL, Marta P.: Francisco Pacheco y su Libro de Retratos. Madrid, 2011; y MUÑOZ RUBIO, María del Valme y CANO RIVERO, Ignacio (eds.): Francisco Pacheco. Teórico, artista, maestro. Sevilla, 2016.

${ }^{4}$ MOLINIÉ, Anne-Sophie: "Giorgio Vasari, Francisco Pacheco et le Jugement dernier", Mélanges de la Casa de Velázquez, 41-2, 2011, pp. 165-184. A pesar de las dificultades cronológicas, se afirma que el converso Baltasar del Alcázar (1530-1606) le dedicó un largo poema a este lienzo de 1637, hoy aparentemente perdido, pues es difícil vincularlo con el recogido en la BNE (Ms. 17.524, f. 90) por NÚÑEZ RIVERA, José Valentín: "Rodrigo Fernández de Ribera epigramático y Baltasar del Alcázar: problemas de atribución. Descripción y estudio del manuscrito 17524 de la Biblioteca Nacional”, Criticón, 55, 1992, pp. 53-89; La poesía de Baltasar del Alcázar: análisis textual y edición crítica. Tesis doctoral inédita, Sevilla, Universidad de Sevilla, 1996; "La poesía de Baltasar de Alcázar. Catálogo de las fuentes textuales. II. Impresos e índices", Voz y letra: Revista de literatura, 8, 2, 1997, pp. 77-118; y "La poesía de Baltasar de Alcázar. Catálogo de las fuentes textuales. I. Manuscritos”, Voz y letra: Revista de literatura, 8, 1997, pp. 53-113. DEL ALCÁZAR, Baltasar: Obra poética. Ed. Valentín Núñez Rivera. Madrid, 2001.

5 Al que dedicó una silva el amigo poeta y caballero de San Juan Antonio Ortiz Melgarejo, miembro de la academia del duque de Alcalá, publicada por el propio Pacheco en su tratado de 1649, tras haberlo recogido en sus "Tratados de erudición de varios autores. Año 1631". Madrid, BNE, Ms. 1713, ff. 178-179. BASSEGODA I HUGAS, en PACHECO, Francisco: Arte de la pintura. Ed. Buenaventura Bassegoda i Hugas. Madrid, 1990 y $2009^{3}$, pp. 339-340 de su largo capítulo en pp. 307-340. Esta obra fue contratada el 28 de julio de 1610 con el comerciante con las Indias -y tal vez indiano- Hernando de Palma Carrillo e Inés Carrillo -y su hijo el licenciado Juan Carrillo de Palma- para su altar funerario, según una inscripción redactada por su amigo el maestro Francisco Medina (1544-1615) (Véase VRANICH, Stanko B.: Francisco de Medina (1544-1615): maestro de la escuela sevillana. Sevilla, 1997), a modo de firma sobre una piedra en escorzo: "Futurum 
del Triunfo y refección de Cristo en el desierto (Figura 3), "pintura... muy bien acompañada e historiada" de San Clemente el Real ${ }^{6}$, estos dos últimos han terminado en el Musée Goya de Castres.

Dedicaremos estas páginas a este último cuadro, de grandes dimensiones (286 x $418 \mathrm{~cm}$ ), firmado y fechado "Fran[cis] ${ }^{\text {cus }}$ Paciecus 1616" (Figura 4), y que

ad finem saeculorum Iuditium, Franciscus Paciecus Romulensis depingebat Saeculi a Iudicis natali XVII Anno XI". Sin embargo, se concluyó el retablo y altar, diseñado por Juan de Oviedo y ejecutado por Juan Martínez Montañés, en 1614, fecha en la que también Pacheco dio por acabado su trabajo y corresponde, en realidad, con la cartela del lienzo de Castres: "Fvtvrvm ad Finem Saecvlorevm Ivdicivm Franciscrs Paciecrs Romvlensis dePingebat, SAeCuli ivdicis natali Decimiseptimi A. Xiv". El gran dibujo preparatorio $(55,4$ x 38,7 cm) del Museo del Prado, que todavía no incluye el autorretrato de Pacheco, debiera fecharse hacia 1610-1611, careciendo de la firma de "postrero de mayo de 1617" que a veces se le ha asignado mientras estaba en la colección de los condes de Alcubierre de Madrid. NAVARRETE PRIETO, Benito: "A New Preparatory Drawing for Francisco Pacheco's Last Judgement. Creative Process and Theological Approval", Master Drawings, xlviii, 4, 2010, pp. 435-446. Pacheco recopiló en sus citados "Tratados de erudición de varios autores. Año 1631" (Madrid, BNE, Ms. 1713) diferentes pareceres sobre este lienzo que él mismo promovió, algunos de cuyos fragmentos publicó en 1649, entre ellos los del predicador franciscano fray Bernardino de los Ángeles, el licenciado y capellán Antonio de Santiago, el doctor teólogo Alonso Gómez de Rojas (†1649), canónigo de Sevilla y visitador y examinador general del arzobispado, y del jesuita Gaspar de Zamora (1543-1621) sobre la edad de los resucitados. El maestro [Alonso de] Alfaro también le dedicó un poema -"[i]Con qué divino Genio el arte impeles?"- en alabanza a este mismo lienzo del Juicio Final de Pacheco, quien lo recogió en su cartapacio manuscrito "Poesías Varias. Año 1631" (Ms. Span 56, f. 122, de la Houghton Library, Harvard University, Cambridge, Mass.), que incluye unos doscientos poemas atribuidos o firmados por diferentes poetas. El poeta sevillano Melchor de Alcázar (1588-1625) le dedicó otro poema: "El día de lamento i de ira lleno. Estanças al cuadro del juizio [de Pacheco] que no se acabaron del mismo", en ff. 167v-168v [Al final: no passò adelante]. Véase MONTERO, Juan: "El ms. Span 56 de la Houghton Library (Universidad de Harvard): índice topográfico", en AZAUSTRE GALIANA, Antonio y FERNÁNDEZ MOSQUERA, Santiago (eds.): Compostella Aurea. Actas del VIII Congreso de la AISO 2008. T. I. Santiago de Compostela, 2008 [2011], pp. 343-353. Véase en general, BASSEGODA I HUGAS, Bonaventura: "Las tareas intelectuales del pintor Francisco Pacheco", en Symposium Internacional Velázquez. Actas del Symposium Internacional Velázquez 1999. Sevilla, 2004, pp. 39-46; CACHO CASAL, Marta P.: Francisco Pacheco..., op. cit., pp. 242-253; MÉNDEZ RODRÍGUEZ, Luis: “Ut pictura poesis. Los pintores poetas en la Sevilla del Siglo de Oro”, en LOZA AZUAGA, María Luisa (ed.): Juan de Arguijo y la Sevilla del Siglo de Oro. Sevilla, 2017, expobus.us.es/omeka/files/original/e7ea4d24966aeb476cac75838fa106b2.pdf (consultado el 20-7-2018).

${ }^{6}$ PALOMINO DE CASTRO Y VELASCO, Antonio [Acisclo]: El Museo pictórico y Escala Óptica (1715). El Parnaso español pintoresco laureado (Madrid, 1724). Madrid, 1947, pp. 871-873. 
hasta $1810^{7}$ ocupó el frente del refectorio del convento de San Clemente el Real de Sevilla ${ }^{8}$. Ya había realizado, entre 1610 y 1613, un retablo dedicado a San Juan Bautista para este mismo convento, ejecutado por Gaspar Núñez Delgado y Francisco de Ocampo, y contratado con las monjas y hermanas de sangre Bernarda Sande de Carvajal y Petronila de Carvajal ${ }^{9}$. Hemos de suponer que Pacheco fue contratado por las religiosas cistercienses bernardas ${ }^{10}$, aunque quizá no nuevamente por las hermanas, sino a instancias del licenciado Antonio de

${ }^{7}$ Sobre su ulterior historia, sabemos que pasó a la colección privada del I Duc de Padoue (desde 1807), primo de Napoleón Bonaparte, Jean-Thomas Arrighi de Casanova (1778-1853), que había estado en España en 1808-1809 y quien reunió hacia 1838 una galería española, en paralelo y contemporáneamente a la de Louis-Philippe del Louvre. Pasó así pues al Domaine Courson (Île-de-France), antes de aparecer en el comercio artístico de París, y ser adquirido por el Museo de Castres en 1993.

8 VALDIVIESO, Enrique y SERRERA, Juan Miguel: Pintura sevillana del primer tercio del siglo XVII. Madrid, 1985, p. 74, cuando todavía se encontraba en Courson; BATICLE, Janinne: "La galérie espagnole de Courson", en Le Domaine de Courson, la demeure historique, 1983; VALDIVIESO, Enrique: Historia de la pintura sevillana. Sevilla, 1986, p. 166; VALDIVIESO, Enrique: Francisco Pacheco (1564-1644). Sevilla, 1990, pp. 26-27; VALDIVIESO, Enrique: Pintura barroca sevillana. Sevilla, 2003, pp. 112-134; PACHECO, Francisco: Arte de la pintura (1649). Ed. Buenaventura Bassegoda i Hugas. Madrid, 1990 y 2009³ pp. 634-640 (1649, III, xiii, pp. 531-534); AUGÉ, Jean-Louis: "Le Christ servi par les anges dans le désert de Francisco Pacheco", en Regards sur..., 1, 1993, n 1, pp. 2-9; 1997, pp. 27-29; AUGÉ, Jean-Louis: "Velázquez et Francisco Pacheco: nouvelles perspectives à propos d'une peinture savante des débuts du Siècle d'Or", Le Cahiers du musée Goya, 1, 1999; AUGÉ, Jean-Louis: "Diego Velázquez et Francisco Pacheco: l'apprentissage d'un génie de la peinture (1611-1611)", en BARBÉ-COQUELIN DE LISLE, Geneviève (ed.): Velázquez aujourd'hui. Biarritz, 2002-2003, pp. 35-43; AUGÉ, Jean-Louis: "Diego Velázquez y Francisco Pacheco: el aprendizaje de un genio de la pintura, 1611-1616", en Symposium Internacional Velázquez. Actas del Symposium Internacional Velázquez 1999. Sevilla, 2004, pp. 33-37; y AUGÉ, Jean-Louis (ed.): Inventaire général des collections du musée Goya, Tome I, Peintures hispaniques. Castres, 2005, n 42 , pp. 68-69, para quien Velázquez habría pintado la naturaleza muerta del centro del cuadro en su conjunto, tras establecer una comparación a partir de su radiografía. También BASSEGODA, Bonaventura: "Pacheco y Velázquez", en Velázquez y Sevilla. T. II. Sevilla, 1999, pp. 124-139; DELENDA, Odile: "Pacheco, Velázquez et les Jésuites", en BARBÉ-COQUELIN DE LISLE, Geneviève (ed.): Velázquez aujourd'hui. Biarritz, 2002, pp. 45-67; y MUÑOZ RUBIO, María del Valme y CANO RIVERO, Ignacio (eds.): Francisco Pacheco..., op. cit.

9 Ignoramos la relación que pudo tener con el religioso agustino mexicano fray Juan Agustín de Carvajal (1558-1618), obispo de Huamanga en el Perú, donde murió y por el que se erigía en Sevilla, en 1622, como acreedora de sus bienes sor Petronila Duarte (o Sande) de Carvajal, monja profesa en el convento de San Clemente de Sevilla.

${ }^{10}$ BORRERO FERNÁNDEZ, Mercedes; VILLANUEVA, Fernando y FERNÁNDEZ, Rufina: El real monasterio de San Clemente de Sevilla. Historia. Rehabilitación. Archivo. Sevilla, 1991; y BORRERO FERNÁNDEZ, Mercedes: "El Real Monasterio de San 
Santiago, capellán mayor del convento de San Clemente el Real de Sevilla; no obstante, esta vía de investigación también se cierra, pues de este nada sabemos más allá del informe que sobre el Juicio Final de Pacheco había dado este sacerdote $^{11}$. Y con ellas queremos rendir nuestro muy amistoso homenaje a Vicente Lleó Cañal quien, desde su juvenil Sevilla Nueva Roma, abrió la senda del estudio contextualizado, social e ideológicamente del arte sevillano, y quien no ha dejado de enriquecer nuestro conocimiento sobre el primer Seiscientos por el que también nos moveremos en estas páginas ${ }^{12}$.

Pintado muy probablemente entre 1615 y 1616, la iconografía del lienzo del Triunfo y refección de Cristo en el desierto o, como ahora lo conocemos, Cristo servido por los ángeles, es relativamente excepcional en el ámbito del arte europeo ${ }^{13}$, si excluimos algunos ejemplos precisamente pintados en la Sevilla de comienzos del siglo XVII ${ }^{14}$.

Clemente. Expresión del monacato femenino sevillano", en Real Monasterio de San Clemente: historia, tradición y liturgia. Córdoba, 1999, pp. 27-76.

${ }^{11}$ Recogido en 1631 en su "Tratados de erudición de varios autores", ff. 119/120-125v y en 1649 por el propio autor. PACHECO, Francisco: Arte de la pintura, op. cit., pp. 318-322.

12 Desde LLEÓ CAÑAL, Vicente: "The Cultivated Elite of Velázquez's Seville", en Velázquez in Seville, Edimburgo, 1996, pp. 23-27; Ut pictura poesis (Pintores y poetas en la Sevilla del Siglo de Oro). Sevilla, 2007; "La Sevilla del Siglo de Oro: ortodoxias y heterodoxias", en PORTÚS PÉREZ, Javier (ed.): Fábulas de Velázquez. Mitología e historia sagrada en el Siglo de Oro. Madrid, 2007, pp. 95-113; "Velázquez y los círculos intelectuales de Sevilla”, en NAVARRETE PRIETO, Benito (ed.): El joven Velázquez: a propósito de La Educación de la Virgen de Yale. Sevilla, 2015, pp. 228-241; "Séville 1600: une nouvelle Renaissance?", en KIENTZ, Guillaume (ed.): Velázquez. París, 2015, pp. 40-47; a su "La Congregación de la Granada y los artistas sevillanos del Barroco", en MATA INDURÁIN, Carlos y MORÓZOVA, Anna (eds.): Temas y formas hispánicas: arte, cultura y sociedad. Pamplona, 2015, pp. 201-217, compartido en San Petersburgo, con la no menos inestimable Santu, en 2014.

${ }^{13}$ RÉAU, Louis: Iconographie de l'art chrétien. París, 1957; e Iconografia del arte cristiano. Iconografía de la Biblia, Nuevo Testamento. T. 1, 2. Barcelona, 1996, pp. 321-322. Este autor señaló algunos frescos y capiteles de la Francia del siglo X, Fra Angelico en el convento de San Marco de Florencia, Perugino en la Pinacoteca Vaticana, un grabado de la escuela de Martin Schongauer (Cleveland Museum of Art), una tabla de Dello Delli en el retablo de la catedral vieja de Salamanca; también un lienzo de Ludovico Carracci (Musée de Lyon) y otro tal vez en Berlín, en el que Cristo se lava las manos, otro de Giovanni Lanfranco (Museo Nazionale de Capodimonte, de Nápoles) y un tercero de Charles Lebrun (Musée du Louvre).

${ }^{14}$ LAFUENTE FERRARI, Enrique: "La vida de un tema iconográfico en la pintura andaluza", Archivo español de arte y arqueología, 39, 1937, pp. 235-258. También sevillano sería el también enorme lienzo ( $240 \times 423 \mathrm{~cm}$, aunque supuestamente reducido en sus medidas), de 1627, de Jerónimo Ramírez (firmado "Jeronimo Ramires fecieba año 1627”) de 
Dada la relativa falta de importancia de los precedentes españoles - que con Dello Delli en Salamanca habrían tal vez conectado con la tradición iconográfica más rica, la bizantina, para este tema-debiéramos pensar con Enrique Lafuente Ferrari que, aunque no se conociera realmente este segundo lienzo, la composición de Pacheco dependiera del que, hacia $1600^{15}$, había pintado el racionero cordobés Pablo de Céspedes (1538-1608), también un cuadro enorme (290 x $320 \mathrm{~cm}$, aunque en 1810 se daban unas medidas de 320 x $415 \mathrm{~cm}$ ), recientísimamente identificado por Navarrete Prieto en el Palacio Real de Madrid (Patrimonio Nacional, inv. 10010252, al menos desde 1811 y con seguridad desde antes de 1874 y procedente del Alcázar de Sevilla donde aún estaba en 1810) ${ }^{16}$, y que procedía en origen de otro refectorio, acabado en $1593^{17}$, el de la Casa Profesa de la Anunciación de Sevilla ${ }^{18}$ (Figura 5). La localización de sendos lienzos quedaba justificada por

la parroquia de San Lorenzo de Sevilla, aunque se ha pensado que también procediera de un refectorio conventual de la ciudad.

${ }^{15}$ Se ha fechado a partir de la datación de su otro lienzo, de La aparición de la Trinidad a San Ignacio de Loyola, que Céspedes también pintó para la Casa profesa sevillana, hoy en el paraninfo de la Universidad de Sevilla, desechándose las atribuciones previas al anónimo Maestro de San Hermenegildo o a Juan Luis Zambrano (1598-1639). Recordemos que el retablo mayor de su iglesia (1604-1606), de Alonso Matías, incluyó pinturas de Girolamo Lucenti da Correggio, Juan de Roelas y Antonio Mohedano.

${ }^{16}$ NAVARRETE PRIETO, Benito y MARTÍNEZ LARA, Pedro Manuel: "Cristo servido por los ángeles de Pablo de Céspedes y los orígenes del primer naturalismo", Reales Sitios, 202, 2015, pp. 34-51. Ahora en general, DÍAZ CAYEROS, Patricia: "Pablo de Céspedes entre Italia y España”, Anales del Instituto de Investigaciones Estéticas, xxii, 76, 2000, pp. 5-60; y MARTÍNEZ LARA, Pedro Manuel: Pablo de Céspedes. Estudio de los procesos de producción y asimilación entre Italia y España, entre el Renacimiento y el Barroco. Tesis doctoral, Universidad de Sevilla, Sevilla, 2012. Recoge elementos de un dibujo atribuido al racionero Céspedes (22,5 x 29,8 cm, París, Colección particular). Se ha de desechar como fuente el dibujo atribuido a Céspedes por Lafuente Ferrari, de la antigua colección Félix Boix y hoy en Nueva York, The Hispanic Society of America, que se atribuye actualmente a Alonso Cano, Juan de Valdés Leal o Pedro Atanasio Bocanegra.

${ }^{17}$ RODRÍGUEZ G. DE CEBALLOS, Alfonso: Bartolomé de Bustamante y los orígenes de la arquitectura jesuítica en España. Roma, 1966, p. 153.

${ }^{18}$ Sobre esta, véase DE ROA, Martín: Historia de la Provincia de Andalucía de la Compañia de Jesús (1553-1662). Eds. Antonio Martín Pradas e Inmaculada Carrasco Gómez. Écija, 2005; y DE SOLÍS, Antonio: Los dos espejos. Historia de la Casa Profesa de la Compañia de Jesús en Sevilla durante sus dos primeros siglos 1550-1765 [1765]. Ed. Leonardo Moreno García. Sevilla, 2010. También MORALES, Alfredo J.: "La arquitectura jesuítica en Andalucía. Estado de la cuestión”, en ÁLVARO ZAMORA, María Isabel; IBÁÑEZ FERNÁNDEZ, Javier y CRIADO MAINAR, Jesús (eds.): La arquitectura jesuítica. Actas del Simposio internacional. Zaragoza, 2012, pp. 327-353; y O’NEILL, Charles E. y DOMÍNGUEZ, Joaquín María: Diccionario histórico de la Compañía de Jesús. Biográfico-temático, Roma-Madrid, 2001, IV. No sabemos de quién pudo salir el encargo, al escapársenos la fecha del lienzo, habiendo sido prepósito de la Casa profesa entre 
su temática, en sustitución de la más tradicional Última Cena, y su significación tanto eucarística en sentido estricto como de acción de gracias por los alimentos que los profesos o las monjas se aprestaban a recibir.

Este origen hispalense podría justificar también la hipótesis de Lafuente Ferrari, que hallaba como punto de partida los Ejercicios espirituales de San Ignacio de Loyola, quien a su vez había dedicado una sección de "Los misterios de la vida de Cristo" al tema, sobre los evangelios de Lucas, 4, 5 y de Mateo, 4, 11, para limitarse en tercer lugar a reflexionar sobre el pasaje "Vinieron los ángeles y le servían", sin mayores precisiones. No obstante este laconismo y las afirmaciones historiográficas sobre la incidencia temprana de aquellos ejercicios sobre la actividad artística, estamos lejos de tener una idea clara sobre su práctica real ${ }^{19}$, y sobre la incidencia retórica de los pasajes recomendados. De hecho, a pesar de que los Exercitia spiritualia se habían publicado en 1548 en Roma (Antonio Bladio, 1548), la primera edición de los mismos en castellano no vio la luz, nuevamente en Roma, hasta 1615 (Exercicios spirituales del B. P. Ignacio de Loyola, Roma, Collegio Romano de la Compañía de Iesús, 1615), apareciendo solamente más ediciones a partir de 1622, fecha de la canonización de San Ignacio. Hasta 1601 fue prepósito de la Casa el padre Antonio Cordeses (1518-1601), autor de una póstuma obra, el anónimo Itinerario della perfezione cristiana (Florencia, 1607 y 1614), traducido del español.

Por su parte, el jesuita Pedro de Ribadeneyra, en la primera parte de su Flos sanctorum (Madrid, Luis Sánchez, 1604 y 1616, p. 10), que otras veces utilizó Pacheco, fue absolutamente lacónico al propósito: “... el Señor quedó vencedor, y triunfador: y los Ángeles del cielo que estaban a la mira, vinieron a servirle, y le traxeron de comer". Su antecesor Alonso de Villegas le había dedicado al "ayuno y tentaciones" el capítulo xi de su Flos sanctorum. Historia general de la vida y hechos de Iesu Christo (Madrid, Pedro Madrigal, 1588, ff. 14-15v), subrayando la primera tentación del demonio, y el rechazo de Cristo de convertir para su sustento las piedras en pan, para concluir de forma algo menos escueta: "quedando Jesu Christo con vitoria, baxaron millares de ángeles, que auían estado a ver el sucesso de la batalla y vinieron a él con gran júbilo, y alegría, magnificando altamente su vitoria, diziendo, que muy bien auía vengado a Adán; truxéronle manjares del cielo que comió con mucho gusto, y recreo, porque assí lo suele hazer Dios al que desecha el pan de piedras que le ofrece el demonio (porque tales son todos sus pasatiempos y placeres duros y desabridos), pagóselo con darle pan del

1602 y 1608 el padre Ignacio Yáñez (1555-1621), otro de los poetas del citado Cancionero sevillano B 2495.

${ }_{19}$ Véase IPARRAGUIRRE, Ignacio: Historia de la Práctica de los Ejercicios Espirituales de San Ignacio de Loyola. Roma, 1946-1954. Y la edición póstuma del curso de 1945-1946 de BATAILlON, Marcel: Les Jésuites dans l’Espagne du XVI siècle. París, 2009, y ed. esp.: Los jesuitas en la España del siglo XVI. Valladolid, 2010. 
cielo y manjar de su celestial mesa que son gustos y regalos maravillosos, de que goza su alma en este mundo en prendas y señal de la vida eterna, de que después ha de gozar en el cielo".

Estos pasajes no parecen suficientes para explicar el cuadro de Pacheco, que requeriría de otros textos u otras imágenes, como veremos, centrado en la bendición de los alimentos. No obstante, aunque fuera a posteriori, Pacheco se refirió en su Arte de la pintura a este episodio evangélico ${ }^{20}$, y sus referencias textuales van por otra dirección. Partió como es lógico del fragmento de Mateo $(4,11)$, "Victoria itaque facta, venerunt Angeli et ministrabant ei", para después servirse de San Bernardo: "llegáronse los ángeles y como a triunfador le servían, habiéndolos tenido ausentes porque osase llegar el Demonio, y porque su victoria fuese más excelente, venciendo solo al Enemigo; servíanle, trayéndole de comer, haciéndole reverencia, adorándolo humildemente como a su Dios y Señor nunca vencido, dice San Bernardo".

Siguiendo estas notas, Bonaventura Bassegoda i Hugas nos reenvió en 1990, por su parte, a un texto de Landulfo de Sajonia el Cartujano, la Vita Christi. Primera Parte, publicada en Sevilla en 1630, una cita correcta para 1649 pero no para 1616; en realidad se trata de un texto de San Bernardo de Claraval, un "Serm[ón] de Iejun[io et tentatione] Dni”, recogido por el Cartujano en esa edición (cap. 22, ff. 151v-152): [de ieiunio -ayuno-Domini in deserto] “... pues si quieres tú ser servido de los ángeles huye de las consolaciones deste siglo y resiste a las tentaciones del diablo y menosprecia que tu ánima sea consolada en las otras cosas transitorias...", que se desvía el texto del pintor de Sanlúcar.

Lafuente Ferrari, en 1937, nos había dirigido hacia San Buenaventura y sus Meditationes Vitae Christi a partir de una de sus innumerables ediciones ${ }^{21}$; en el imaginativo pasaje relativo, Cristo pedía a los ángeles que le llevaran la comida que su madre solía hacerle a él, para sí misma y para San José, y bendecía las viandas que traían, de acuerdo con la tradición de los hebreos recogida en la Torá, añadiríamos nosotros; tras un excursus sobre los alimentos proporcionados por Dios, seguían unos párrafos en los que el autor se imaginaba cómo los ángeles habían ido a la casa de María, quien les había dado el guiso preparado para su comida, pan, vino y pescado, junto a una toalla o servilleta y manteles, y de vuelta unos ángeles le servían mientras otros cantaban ${ }^{22}$.

${ }^{20}$ PACHECO, Francisco: Arte de la pintura, 1649, III, x, p. 534: "Pintura del ayuno del Salvador y tentaciones del demonio"; y 1990, pp. 634-640.

${ }^{21}$ LAFUENTE FERRARI, Enrique: "La vida de un tema iconográfico...", op. cit., p. 244, a partir de una edición de 1568 de Lyon.

22 "Victoria itaque facta, venerunt Angeli et ministrabant ei. Hic autem diligenter attende et conspice Dominum comedentem, solum circunstantibus angelis et considera bene omnia quae sequentur, qui pulchra sunt et devota valde. Et quaeso quid Angeli ministrabant, ut comederet post tam longum ieiunium? De hoc scriptura non loquitur. Possumus 
Siendo esta fuente hasta ahora la más explícita, volvamos nuestros ojos a la estupenda écfrasis que el propio Pacheco hizo de su lienzo ${ }^{23}$ : "A la boca de una cueva de peñascos, una mesa sobre uno de ellos; y, en medio de lo más ancho, sentado Cristo en otro, con su túnica y manto carmesí y azul, levantando los ojos al cielo y las dos manos bendiciendo la mesa y el pan al modo antiguo, como el

autem hoc victoriosum prandium sicut volumus ordinare... Dicunt ei angeli: Domine, multum jejunastis, quid vultis ut vobis paremus? Et ille: Ite ad matrem meam charissimam, et si quid habet ad manus, deferte; quia de nullis cibis sic libenter vescor, sicut de suis. Tunc duo ex ipsis pergentes in momento fuerunt cum ea, et eam reverenter salutantes, ambasiatam faciunt, et modicum pulmentum, quod sibi et Joseph paraverat, et panem cum tobalia et aliis opportunis portant; et forte Domina etiam aliquos pisciculos, si potuit, procuravit. Reversi ergo portant in plana terra, et mensas benedictionem solemniter peragunt. Conspice autem eum hic bene in singulis quae agit. Sedet enim in terra composite ac curialiter, et sobrie comedit. Circumstant Angeli ministrantes Domino suo. Alius servit ei de pane, alius de vino, alius parat pisciculos, et alii cantant de canticis Sion, et jucundantur, et idem festum agunt coram eo. Si liceat dici, permixtum est hoc festum compassione permaxima, propter quam et nos deberemus plorare. Conspiciunt enim eum reverenter, et considerantes Deum et Dominum suum, et totius mundi creatorem, qui dat escam omni carni, sic humiliatum, et sustentatione cibi corporalis indigentem, et comedentem sicut caeteros de populo, moventur compassione. Clamares et diceres: O Domine, quanta fecisti! Omnia opera vestra sunt plena stupore. Adjuvate me, ut ego aliqua patiar pro vobis, qui pro me tot et tanta sustinuisti. Certe hoc solum te in eius amorem deberet vehementer accendere. Tandem sumpta refectione, dicit angelis, ut reportent res, et dicant matri, quod cito redibit ad eam. Ipsis autem reversis, dicit omnibus: Redite vos ad Patrem et ad gaudia vera; me enim adhuc peregrinari oportet: rogo autem vos, ut me recommendetis Patri, et toti curiae coelesti. Qui procidentes in terram, et benedictionem petentes, ea recepta, redierunt ad patriam, ejus jussa complentes, et de eius victoria, et de his novis totam coelestem curiam impleverunt". Citamos por la edición de las Opera omnia, Sixti V. Pontificis Maximi jussu... Roma, 1588 (1596), XII, cap. xvii. No parece haberse dado en la época moderna una renovación de esta temática, demasiado "humanizada", en la literatura religiosa o en los comentarios evangélicos, como el del brujense Francis Lucas (ca. 1549-1619), In sacrosancta quattuor Evangelisti Evangelia commentariorum (Amberes, Christofer Plantin, 1606), muy leído en el círculo de Pacheco por estos mismos años.

${ }^{23}$ No muy distantes de otra descripción de Pacheco de otra de sus iconografías de este tema (1649, III, vi; 1990, p. 491), la de la pintura que, para el retablo mayor del colegio de los jesuitas de San Hermenegildo de Sevilla realizaría pocos años después, en 1620, sobre un soporte de jaspe de Granada, junto a un también desaparecido Bautismo de Cristo: "Cristo sentado a la mesa en el desierto, bendiciendo el pan, cuando los ángeles le ministraban la comida después del ayuno; y un ángel como maestresala con una toalla al hombro y un cuchillo en la mano diestra; pan y agua en la mesa y en resplandor y nubes, que hace la piedra, dos ángeles que traen dos platos cubiertos del cielo; los peñascos y países casi los dio el jaspe; el cual formó a una lado de la mesma piedra unos fuegos agraciados y vivos en que se pintó el demonio cayendo vencido en figura de un mal viejo ermitaño con su báculo a manera de garabato". 
sacerdote en la misa; y, por ser antes de la comida, con un pan de a libra; sobre la servilleta, cuchillo y salero, agua en un vaso de barro, con unas uvas en un plato, por principio; a la cabecea de la mesa, y detrás de della, un ángel principal en pie, con su toalla al hombro, como maestresala, con un cuchillo en la mano derecha y con la siniestra alzando la cubierta de un plato con dos róbalos, cocidos, que trae un ángel, que está delante de rodillas, y otro, detrás con unas vinagreras de Talavera señaladas con aceite y vinagre; al lado derecho de Cristo, tres ángeles en pie, con instrumentos músicos, arpa, laúd y lira grande, entreteniendo y solazando a su señor y cantándole la victoria; dos, o más, ángeles niños en el aire, esparciendo flores sobre la mesa; una claridad en el cielo, a la parte izquierda del cuadro, por donde baxan volando, con platos de postres cubiertos y un alegre país, demás de la gran cueva, y desierto, con algunas fieras y animales cerca y lexos".

Contra un fondo en el que se mezclan la roca y un paisaje "de desierto", caracterizado por la presencia de un San Juan Bautista en actitud reverencial y de reconocimiento, con un lejos urbano que debiéramos identificar con Jerusalén, tres angelitos derraman flores sobre la mesa por debajo de un rayo de luz que ilumina la cabeza de Cristo. A la izquierda tres ángeles tañen sus instrumentos, siendo la lira grande una viola de gamba. Al centro, el ángel "maestresala", con un cuchillo en la mano derecha, levanta el plato que cubre un róbalo, como si fuera a aprestarse a limpiarlo; el pescado lo presenta un quinto ángel, mientras un sexto ofrece en una bandeja de loza las vinajeras, identificados por sus iniciales el aceite y el vinagre; en el ángulo superior izquierdo, otros dos ángeles portan por los aires sendos juegos de dos platos de cerámica talaverana, que hemos de suponer encerrarían los postres.

Sobre la mesa rectangular enmantelada, dispuesta en profundidad y con Cristo sentado en uno de los lados mayores, destacan las flores ofrecidas, un salero de peltre, un cuchillo y un limón con el que sazonar el róbalo, una hogaza entera sobre una servilleta doblada, todavía sin fraccionar, un plato con uvas blancas y negras y, en el primer término, un jarro de barro, entre alcarraza y cántaro a la manera del mucho mayor de El Aguador de Sevilla (ca. 1622 [1618/1622], Londres, Wellington Museum-Apsley House) de Diego Velázquez, y a su izquierda un tazón de barro, extraordinario a causa de su naturalismo extremo, más si lo comparamos con el cantarillo adyacente, más convencional que icástico en su imitación de su forma y materia.

Podemos cotejar nuestro lienzo con el dibujo (Figura 6) que se ha identificado como preparatorio (21,7 x 27 cm, "[Luis de] Bargas fec. / 7 de otubre 1615", Barcelona, MNAC, $\left.\mathrm{n}^{\circ} 39.089, \mathrm{~F} 1 \mathrm{c} / 65\right)^{24}$, cuya composición no se aleja demasiado del

${ }^{24}$ Agradezco a los miembros del gabinete de dibujos del MNAC las facilidades para su consulta y la fotografía. Procedente de la Galería Artur Ramón de Barcelona, de la que se adquirió en 1942; procedía a su vez de la colección Félix Boix y Merino (18581932). Véase SÁNCHEZ CANTÓN, Francisco Javier: Dibujos españoles. Madrid, 1930; y 
resultado final; solo falta en este diseño el limón y el plato de uvas, el San Juan Bautista, sustituido en su denotación del paraje desértico por un par de animales, quizá ciervos, y las piedras de primer término, alusión a las que Cristo, en su primera tentación, no había querido convertir en panes.

Si comparamos el lienzo de San Clemente con el de Céspedes para la Casa Profesa de la Anunciación, Pacheco ha girado noventa grados la mesa rectangular en la que, de la mano del cordobés, Cristo adoptaba una posición mayestática y frontal; el fondo de la composición presenta un paisaje de árboles y lejanías mucho más amables; las piedras del suelo y las flores derramadas cubren el primerísimo término. A los extremos, dos ángeles músicos suenan un arpa y una viola de gamba, este dependiente de una estampa de Johann Sadeler, como ha señalado Benito Navarrete. Por encima, cinco ángeles niños, incluso uno con una cesta sobre la cabeza, arrojan flores sobre el comensal. Este homenaje es continuado por dos ángeles mayores situados a la derecha. Otros tres ángeles de los cuatro restantes, a la izquierda, se ocupan de servir la mesa; el primero presenta un cáliz dorado, el tercero una jarra de loza blanca, suponemos de vino; el segundo se aproxima con una bandeja de dulces. Sobre la mesa, cuchillo y servilleta, un aguamanil, un limón cortado, y un pan ya partido, un plato con dos peces y, como postre, un melón y un plato de cerezas. Cristo vuelve los ojos hacia el cielo y bendice los alimentos con las manos alzadas.

En los dos lienzos sevillanos, la acción de partir el pan es secundaria ${ }^{25}$, con respecto a la de la bendición de la mesa y, como se encargaría el propio Pacheco de subrayar, del pan al modo antiguo, como el sacerdote en la misa; abriendo las manos en actitud de oración litúrgica más que uniéndolas o entrelazando los dedos.

Y esta debiera ser, por lo tanto, la función del cuadro de Francisco Pacheco tanto como la del de Pablo de Céspedes. Cristo había superado las tentaciones (Mateo, 4, 1-11, 11 "et ecce angeli accesserunt, et ministrabat ei", "y he aquí vinieron ángeles y le servían"; Lucas, 4, 1-13, 10-11 "scriptum est enim quod angelis suis mandabit de te ut conservent te, et quia in manibus tollent te ne forte offendas ad lapidem pedem tuum", "porque escrito está: A sus ángeles mandará cerca de ti, que te guarden"); y estas ya habían estado prefiguradas en el Antiguo Testamento por las penalidades y tribulaciones del Pueblo de Israel en el desierto del Sinaí; la escena de Cristo, como nuevo Moisés, servido por los ángeles se ha basado en un pasaje de los Psalmos (90/91, 11-12), "pues te encomendará a sus ángeles, para que te guarden en todos tus caminos...", "Quoniam angelis suis mandavit de te, ut custodiant te in omnibus viis tuis. In manibus portabunt te,

ANGULO, Diego y PÉREZ SÁNCHEZ, Alfonso E.: A Corpus of Spanish Drawings, III, Seville School 1600-1650. Londres, 1985, cat. $\mathrm{n}^{\circ}$ 97, plate xxxiv.

${ }_{25}$ Véase al respecto PEREDA, Felipe: Crimen e ilusión. El arte de la verdad en el Siglo de Oro. Madrid, 2017, pp. 40-42, acción que permitiría el reconocimiento del Cristo resurrecto en la cena de Emaús. 
ne forte offendas ad lapidem pedem tuum". Ante estas tentaciones, de la gula, la vana gloria y la soberbia y la avaricia, Cristo no había caído en la tentación, a pesar de su naturaleza humana. Superada la prueba, Cristo da las gracias al Padre Eterno y agradece el reparo de su humanidad, viniere directamente del Cielo o de la casa de su madre en Nazareth. La bendición de los alimentos en un refectorio de sacerdotes jesuitas o de religiosas bernardas asumía el valor de benedicite antes de la comida ${ }^{26}$, la oración de agradecimiento de los alimentos que unos u otras iban a tomar aunque, al mismo tiempo, terrenalizara al Dios-hombre hasta extremos más propios del mundo tardomedieval que del contrarreformístico.

La liturgia de este momento plural, en función de la hora y el día ${ }^{27}$, puede resumirse en el intercambio de oraciones entre el hebdomadario, el lector y la congregación, que seguiría en general las pautas de un "Benedicite, Oculi omnium cum gloria. Kyrie. Pater, et ne nos. Oremus Benedic Domine. Iube Domne post Ps. Tu autem Domine, confiteatur. Agimus. Benedicite, edent pauperes, Kyrie... Pater, Oremus benedic, Tu autem. Memoriam fecit... Benedic, Domine, nos et haec tua dona, quae de tua largitate sumus sumpturi. Per Dominum Nostrum. Amen. Jube domne benedicere. Mensae coelestis participes faciat nos Rex aeternae gloriae. Amen". No obstante, algunas congregaciones seguirían, como mostraría el Breviario cisterciense, que quizá emplearan nuestras bernardas sevillanas, otras: "Benedicite. Oculi omnium in te Sperant, Domine, et tu das escam illorum in tempore opportuno: Aperis tu manum tuam, et impies omne animal benedictione. Gloria Patri. Sicut erat..., Pater noster. E ne nos inducas. Oremus, Benedic, Domine haec dona tua, quae de tua largitate sumus sumpturi. Per Dominum Nostrum. Iube domne benedicere. Mensa coelestis participes faciat nos Rex aeternae gloriae. Amen".

Así pues, en sus diversos y al mismo tiempo análogos contextos, los lienzos de Céspedes y Pacheco cumplirían la función de ejemplarizar el primer benedicite antes de iniciar cualquier refección, imitando al Cristo que agradecía al Padre los alimentos que iba a consumir, tal como había imaginado San Buenaventura más los evangelistas.

Una misma función, pero diversos medios, no solo compositivos y por ende narrativos, sino también dietéticos. La riqueza y variedad de Céspedes ha dado paso a una mucho más frugal comida en el lienzo de Pacheco, uvas, pan, pescado, cuyas connotaciones eucarísticas y participativas saltan a la vista. ¿Y qué bebía Cristo? El cáliz dorado de Céspedes nos predispone a imaginar la jarra blanca

26 JUNGMANN, Josef A.: Las leyes de la liturgia. San Sebastián, 1999, pp. 31-32.

${ }_{27}$ Véase el intento de homogeneización del Ceremonial de los officios diuinos: ansí para el altar, como para el choro y fuera de él, Toledo, 1591, pp. 244-249, en él se especifica la bendición de la mesa en los días que no son de ayuno, en las cenas y en los días de ayuno, y en la colación. 
con vino ${ }^{28}$, pero no hay pista alguna en el incipiente naturalismo objetual del cordobés. Pacheco no es mucho más explícito, aunque las uvas en el plato podrían tener la misma misión del cáliz. El cántaro, en cambio, podría dirigirnos hacia un recipiente de agua, como el del citado lienzo de Velázquez El Aguador de Sevilla (ca. 1622 [1618/1622]), todavía por pintarse años después; pero si en el cántaro velazqueño hay claros indicios de su contenido gracias al naturalismo icástico del joven discípulo, en el del maestro no hay pista ninguna debido a su imagen convencional $^{29}$, aunque algunos historiadores hayan visto, o más bien hayan querido ver, en el conjunto del bodegón de la mesa, la intervención de Diego.

Sobre la mesa, sin embargo, en nuestra opinión, solo hay un objeto que pudiera vincularse con el arte posterior de Velázquez; en el primer término, contrastándose con el citado jarro o cántaro de barro, se destaca el tazón de barro, absolutamente extraordinario a causa de su naturalismo extremo (Figura 7). Pero lo más sorprendente es su identidad con respecto al que aparece en el nuevo lienzo de La educación de la Virgen, de la Yale University Art Gallery de New Haven (Figura 8), para el que se ha propuesto, para aquellos que lo hemos considerado obra autógrafa del joven sevillano, una fecha entre 1615 y 1617 o $1617-1618^{30}$.

Da la impresión de que se trata del mismo tazón, lleno de agua, proyectando su sombra oblicua sobre un plato, ligeramente girado el americano respecto al francés. Los focos de luz proceden de la derecha en Castres y de la izquierda en New Haven, con la consiguiente modificación de la posición de los lustres del agua, pero idéntica iluminación del fondo de la taza a través del líquido incoloro y transparente, y análoga capacidad icástica de imitar los materiales a través del color y la textura aparente. Cabría la posibilidad de una hipotética utilización de

${ }^{28}$ Véase en general CANTERA MONTENEGRO, Enrique: "El pan y el vino en el judaísmo antiguo y medieval”, Espacio, tiempo y forma, III, Historia Medieval, 19, 2007, pp. 13-48.

29 BUSTAMANTE GARCÍA, Agustín y MARÍAS, Fernando: "Entre práctica y teoría: la formación de Velázquez en Sevilla”, en Velázquez y Sevilla. T. II. Sevilla, 1999, pp. 140-157.

${ }^{30}$ MARÍAS, Fernando: "Materia, objetos y pintura en Velázquez", en NAVARRETE PRIETO, Benito (ed.): El joven Velázquez: a propósito de La Educación de la Virgen de Yale. Sevilla, 2015, pp. 243-273. Diferentes opiniones respecto a su atribución a Velázquez, en MARCIARI, John et alt.: The Young Velazquez: "The Education of the Virgin" Restored. New Haven, 2014; y MARCIARI, John: "Más reflexiones sobre atribuciones de autoría y conocimiento experto, en relación con La educación de la Virgen, y en general", en NAVARRETE PRIETO, Benito (ed.): El joven Velázquez: a propósito de La Educación de la Virgen de Yale. Sevilla, 2015, pp. 66-81. También BASSEGODA I HUGAS, Bonaventura: "Velázquez visto por Pacheco: de la perplejidad a la admiración. Apéndice documental", en El joven Velázquez..., op. cit., pp. 346-363. Frente a las claras reticencias de PORTÚS, Javier: "Algunos problemas en La educación de la Virgen”, en El joven Velázquez..., op. cit., pp. 82-99. 
plantillas o imágenes susceptibles de ser calcadas gracias al empleo de papel aceitado $^{31}$, pero los ligeros cambios parecen descartarla, justificadas por las diferentes condiciones lumínicas, en función de su diferente ubicación en el espacio y la iluminación de ficción, de donde se halla el ángel en el lienzo de Yale y de donde proceden las viandas angelicales en el del Musée Goya.

En nuestro Triunfo y refección de Cristo en el desierto, al cierre de 1616, ¿no podríamos imaginarnos una conversación crítica entre el maestro y el discípulo que ve las cosas de otra forma? Y la respuesta del maestro, "pues hazlo tú mejor". Si nuestro Pacheco era según Palomino "pintor especulativo, filósofo, docto, erudito, modesto, poeta, escritor y maestro", el tratadista e historiador habría estado en lo cierto, admitiendo y admirando lo que no llegara a compartir con su minerva y sus pinceles.

Fecha de recepción: 30 de octubre de 2018

Fecha de aceptación: 5 de febrero de 2019

31 Véase GARCÍA-MÁIQUEZ, Jaime: "La cuadratura del círculo: calco y originalidad en la pintura del primer Velázquez”, en El joven Velázquez..., op. cit., pp. 574-593. 


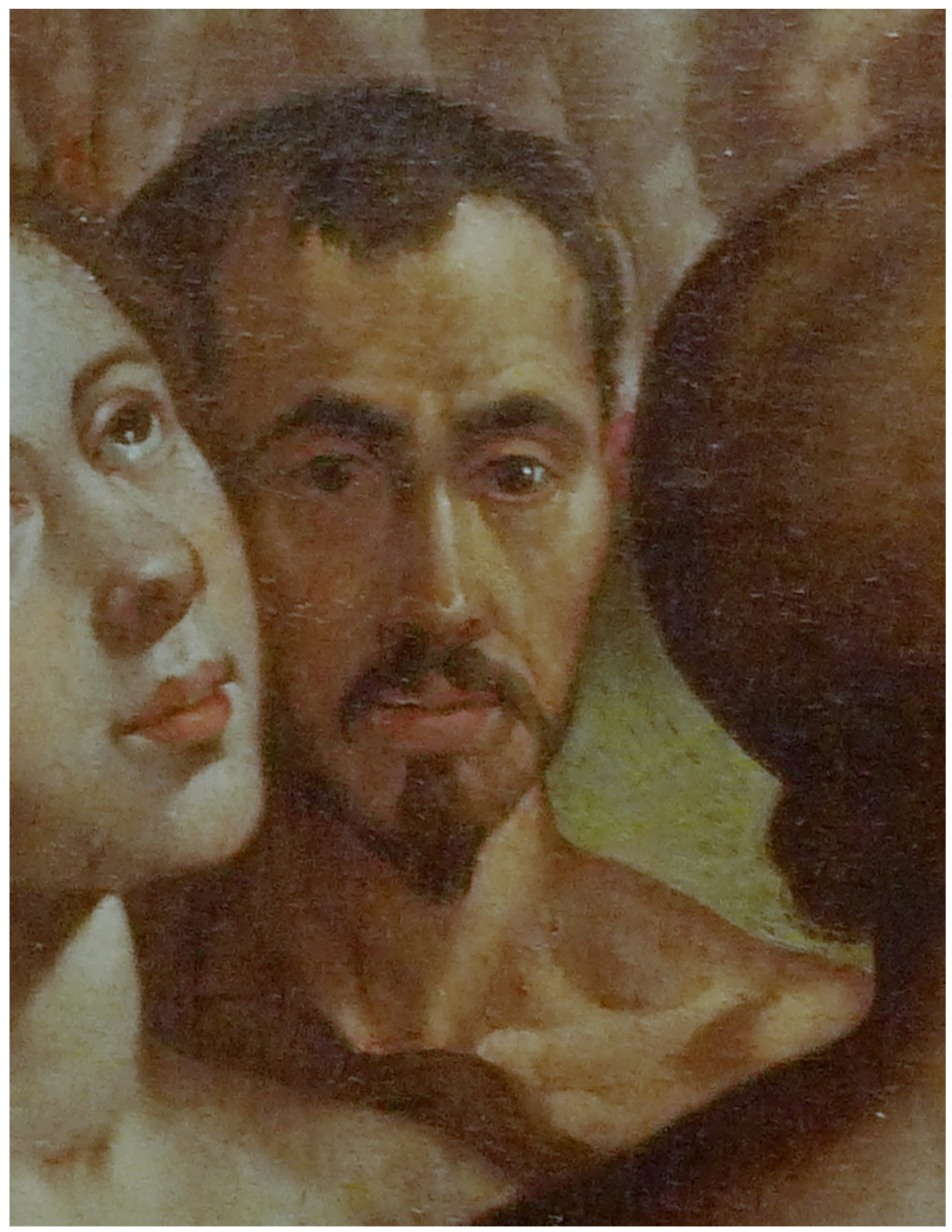

Figura 1. Autorretrato de Francisco Pacheco, Juicio Final, 1610-1611, Castres, Musée Goya. 


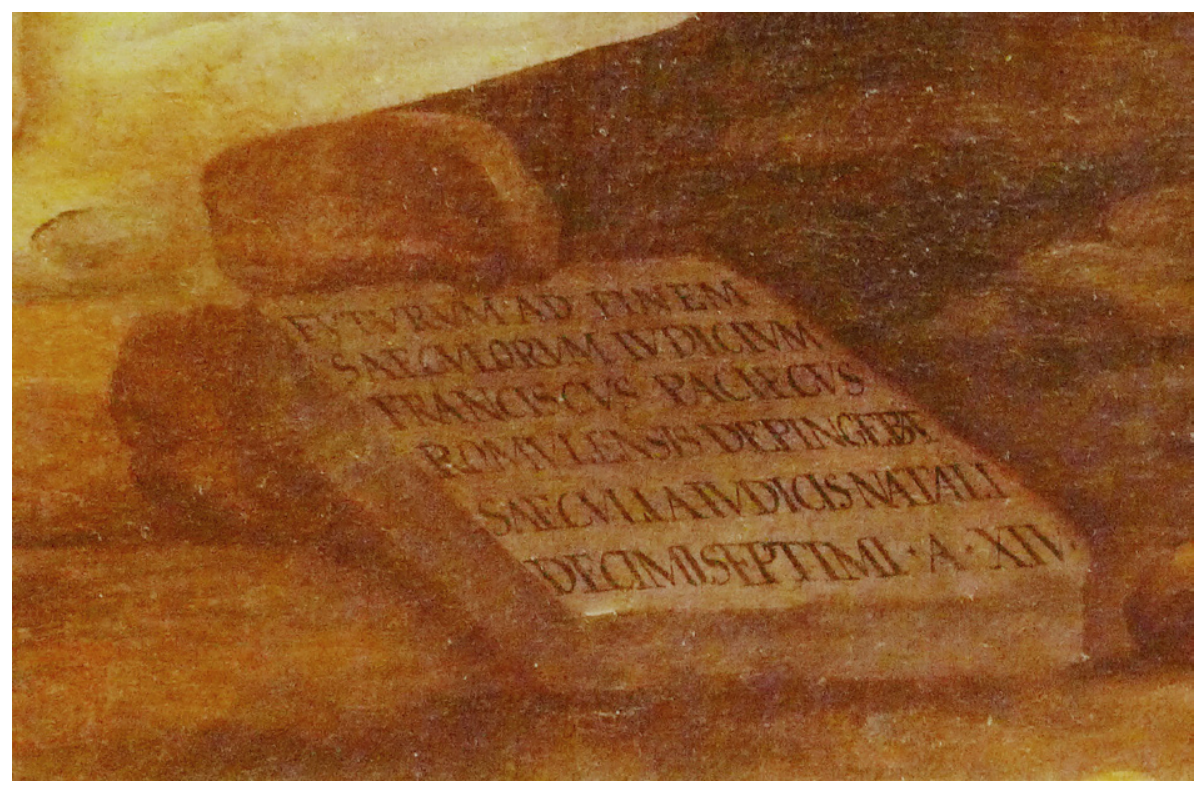

Figura 2. Firma de Francisco Pacheco, Juicio Final, 1610-1611, Castres, Musée Goya. 


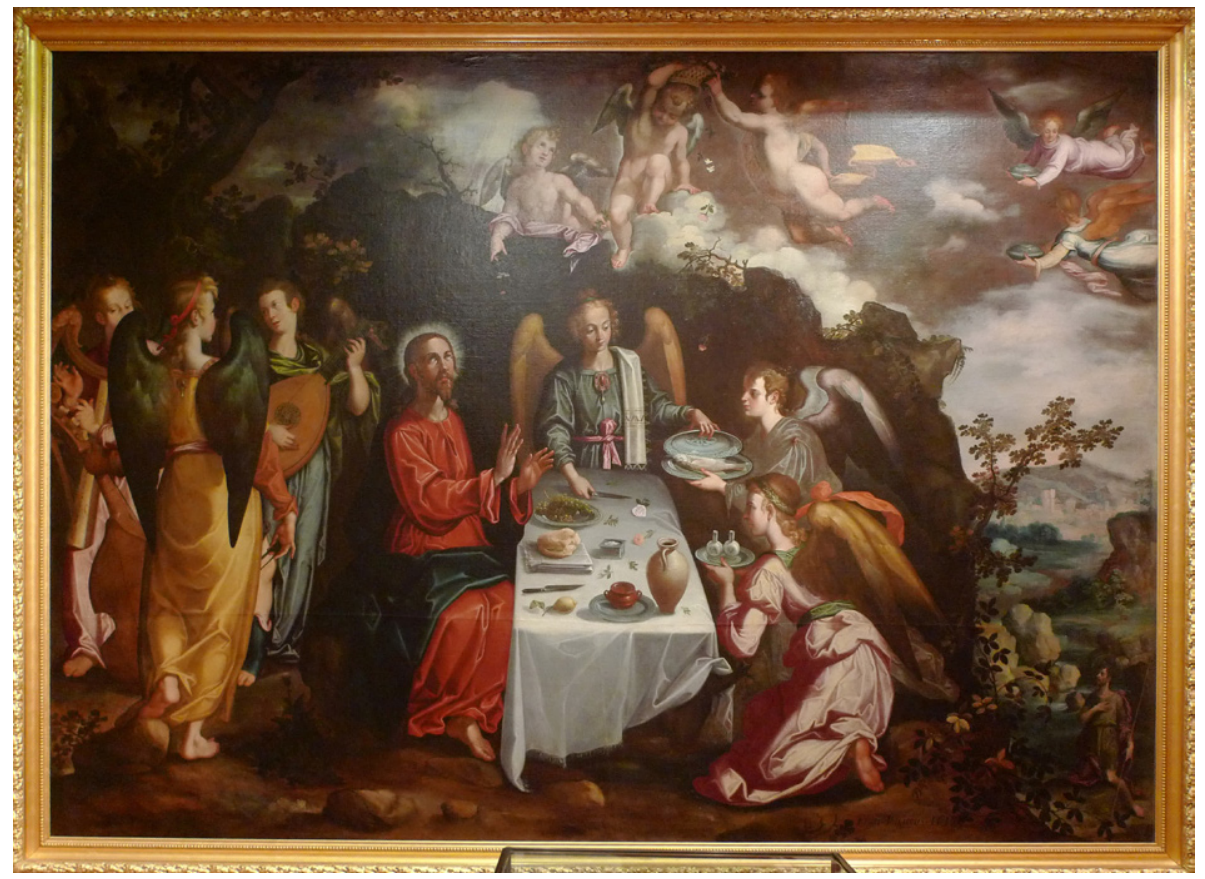

Figura 3. Francisco Pacheco, Triunfo y refección de Cristo en el desierto, 1615-1616, Castres, Musée Goya.

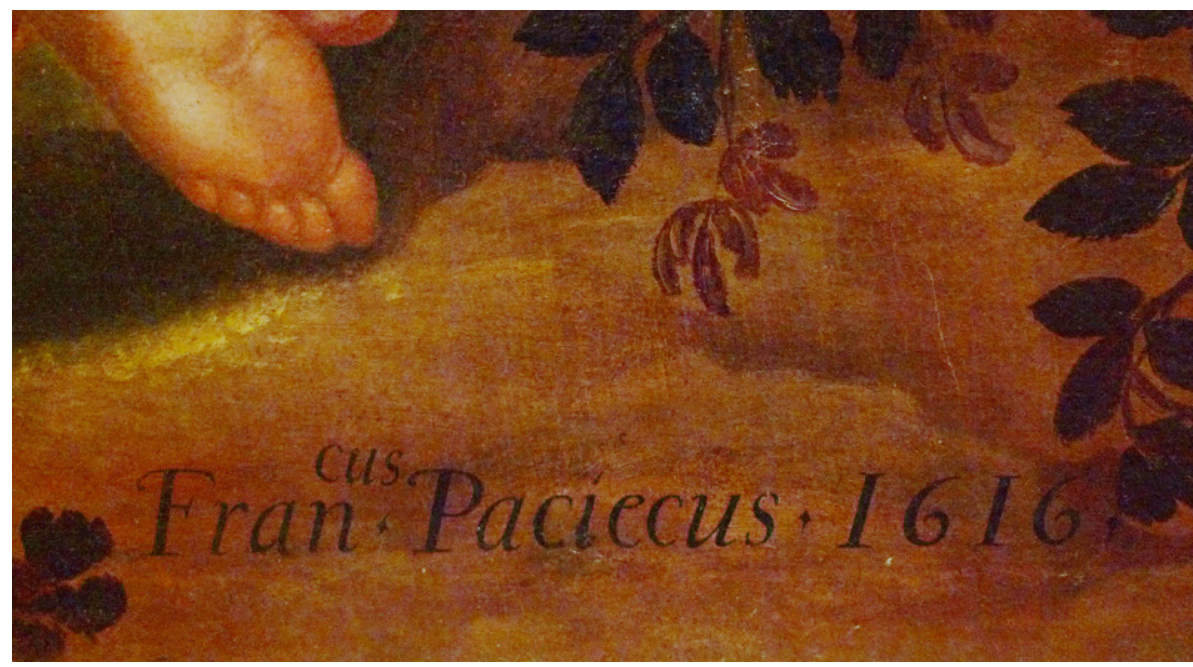

Figura 4. Firma de Francisco Pacheco, Triunfo y refección de Cristo en el desierto, 1615-1616, Castres, Musée Goya.

LABORATORIO DE ARTE 31 (2019), pp. 265-284, ISSN 1130-5762 e-ISSN 2253-8305 - DOI http://dx.doi.org/10.12795/LA.2019.i31.15 


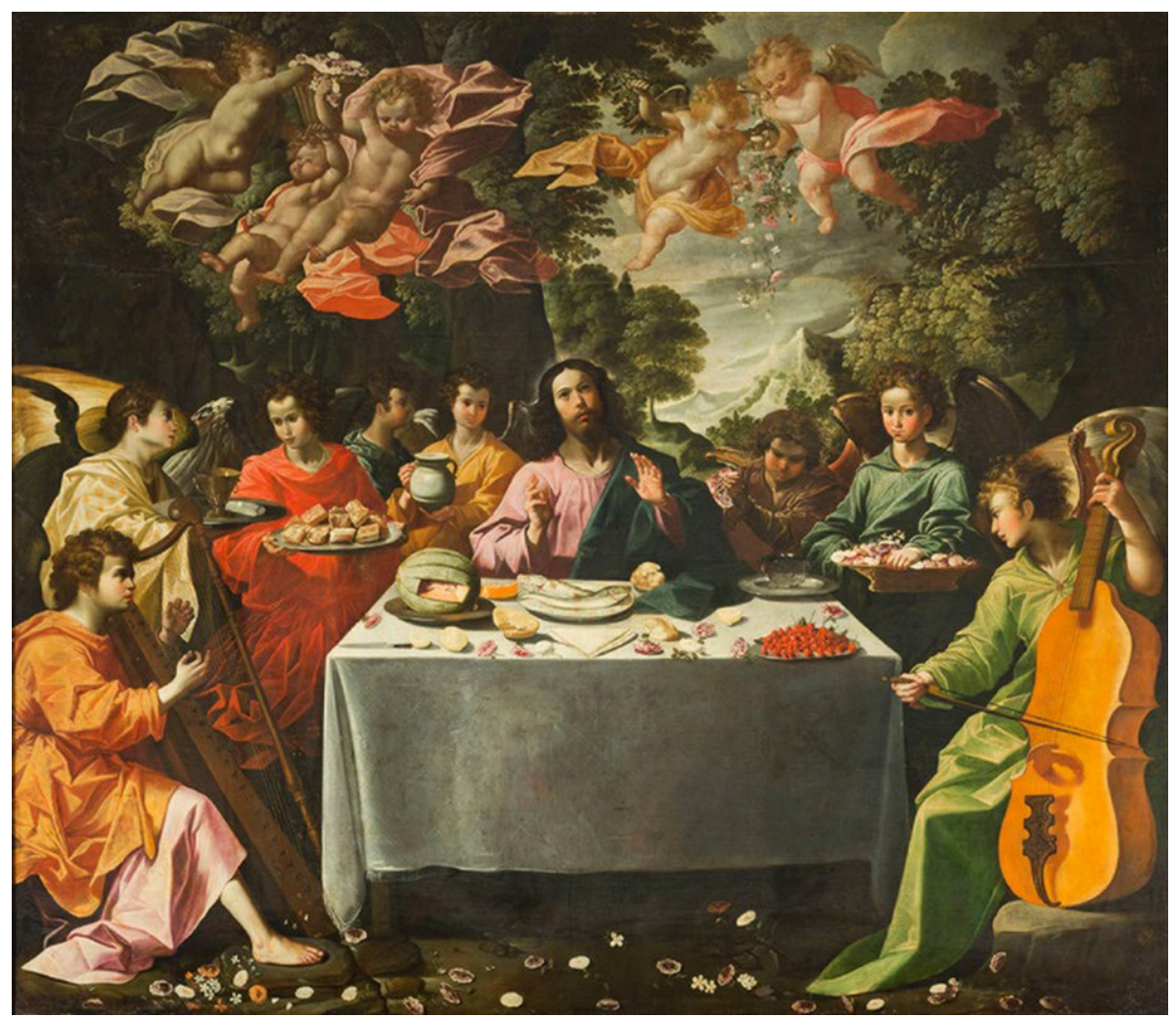

Figura 5. Pablo de Céspedes, Cristo servido por los ángeles, ca. 1600, Madrid, Palacio Real (Patrimonio Nacional, inv. 10010252). 


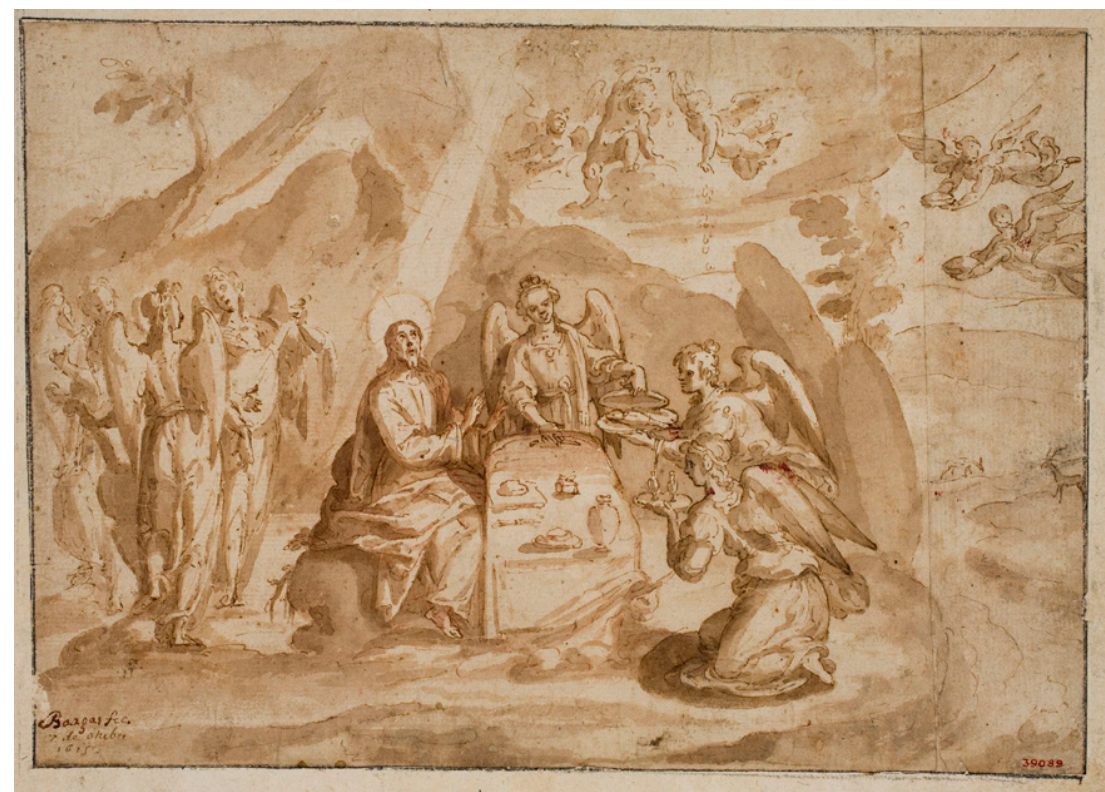

Figura 6. Pablo de Céspedes, Cristo servido por los ángeles, ca. 1600, Barcelona, MNAC (n $\left.{ }^{\circ} 39.089, \mathrm{~F} 1 \mathrm{c} / 65\right)$.

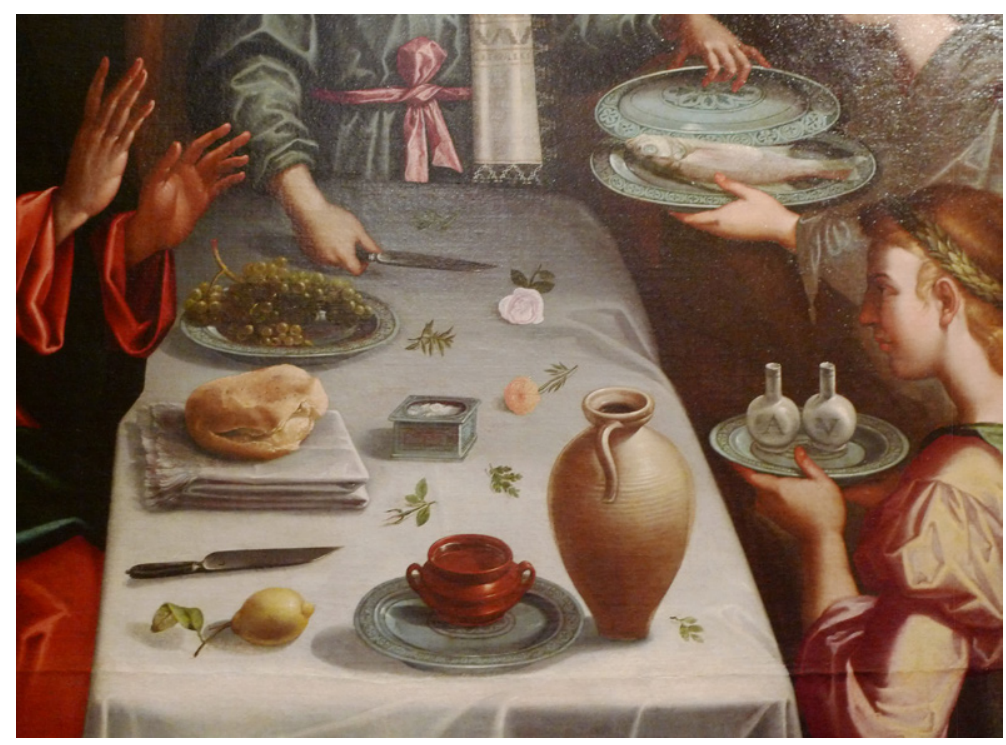

Figura 7. Francisco Pacheco-Diego Velázquez, Triunfo y refección de Cristo en el desierto, 1615-1616, Castres, Musée Goya. 


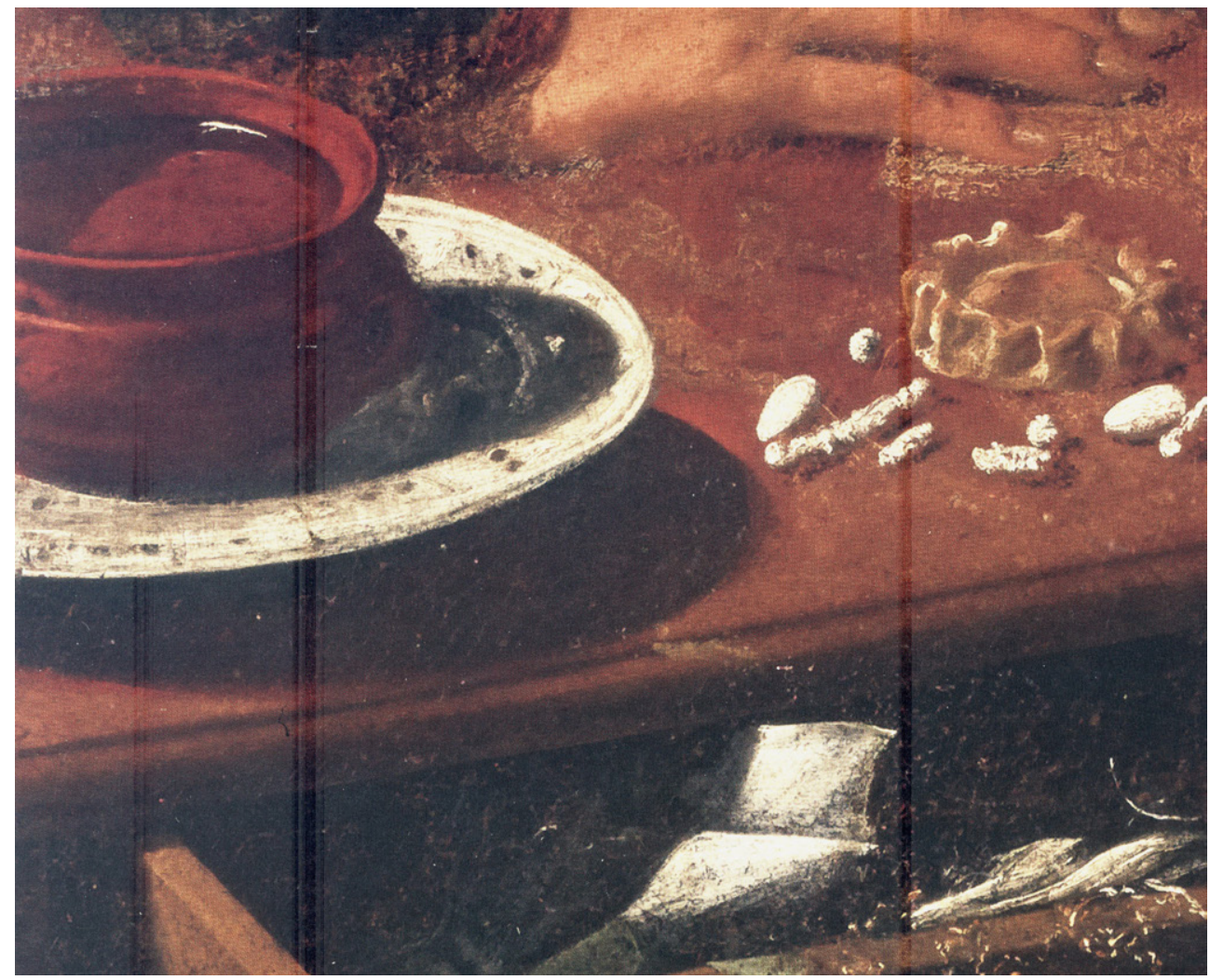

Figura 8. Diego Velázquez, La educación de la Virgen, 1615-1618, New Haven, Yale University Art Gallery. 